\title{
AVALIAÇÃO DO ÍNDICE DE QUALIDADE DA ÁGUA DA LAGOA DE ABASTECIMENTO DA ETA - UNIVAP
}

\section{EVALUATION OF THE IQA (WATER QUALITY INDEX) STUDY CONDUCTED AT THE POND OF THE UNIVAP'S WATER TREATMENT PLANT}

\author{
Ingrid Joseane Pereira ${ }^{1}$ \\ Fernanda Campos Corradini ${ }^{2}$ \\ Fatima Maria Broca ${ }^{3}$ \\ Eduardo Jorge de Brito Bastos ${ }^{4}$ \\ Maria Regina de Aquino Silva ${ }^{5}$
}

Resumo: Este artigo tem como objetivo apresentar o índice de qualidade da água (IQA) feito na lagoa da estação de tratamento da UNIVAP. O índice de qualidade da água (IQA) é um parâmetro de classificação que pode ser obtido por meio da Companhia de Saneamento do Estado de São Paulo (CETESB), no qual apresenta a classificação de ótima, boa, regular e péssima para cada curso de água, lago, lagoa ou rio analisado. Os parâmetros físicos, químicos e biológicos foram comparados aos estipulados pela Resolução CONAMA 357/2005.

Palavras-chave: IQA; resolução CONAMA; parâmetros físicos; parâmetros químicos; parâmetros biológicos.

Abstract: This paper aims to present the water quality index (WQI) made in the pond of the UNIVAP's treatment plant. Water quality index (IQA) is a classification parameter that can be obtained from the São Paulo State Sanitation Company (CETESB), which presents the optimal, good, regular and very poor classifications for each water course, lake, pond or river analyzed. The physical, chemical and biological parameters were compared to those stipulated by CONAMA Resolution 357/2005.

Keywords: IQA; CONAMA Resolution; physical parameters; chemical parameters; biological parameters.

\section{INTRODUÇÂO}

A água é um recurso necessário à vida e manutenção de diferentes atividades como abastecimento humano, irrigação, atividades industriais, dessedentação animal, resfriamento de usinas nucleares e termelétricas, mineração, entre outros.

A qualidade da água na natureza não é totalmente pura devendo esta estar em condições potáveis para o consumo humano, ou seja, livre de contaminantes orgânicos, inorgânicos e de bactérias patogênicas, atraente de aspecto e de sabor agradável para ser bebida, devendo também estar adequada para as finalidades domésticas e

\footnotetext{
${ }^{1}$ Graduada em Engenharia Ambiental e Sanitária, Mestranda em Bioengenharia, Universidade do Vale do Paraíba - Univap, Brasil. Bolsista IGTPAN, E-mail: ingrid_joseane@hotmail.com.br.

${ }_{2}$ Graduada em Engenharia Ambiental e Sanitária, Universidade do Vale do Paraíba - Univap, Brasil. E-mail: fefa.corradini@gmail.com.

${ }^{3}$ Mestre em Ciências Ambientais, Professora, Universidade do Vale do Paraíba - Univap, Brasil. E-mail: fbroca@univap.br.

4 Doutor em Meteorologia, Professor, Universidade do Vale do Paraíba - Univap, Brasil. E-mail: ebbastos@univap.br.

${ }^{5}$ Doutora em Ciências, Professora, Universidade do Vale do Paraíba - Univap, Brasil. E-mail: mregina@univap.br.
} 
atividades industriais (RICHTER, 2009).

O índice de qualidade da água (IQA) foi criado em 1970 nos EUA, nas seguintes décadas adotadas pelos Estados brasileiros, e consiste em métodos utilizados para avaliar a qualidade da água bruta para o abastecimento público, pós-tratamento.

A maioria dos parâmetros avaliados pelo IQA são contaminantes, encontrados no lançamento de esgotos domésticos não contemplando parâmetros também considerados importantes como substâncias tóxicas (metais pesados, pesticidas e compostos orgânicos), protozoários patogênicos e substâncias que interferem nas propriedades organolépticas da água (BRASIL, 2018).

Os parâmetros utilizados na determinação do IQA são: oxigênio dissolvido, coliformes termotolerantes, potencial hidrogeniônico $(\mathrm{pH})$, demanda bioquímica de oxigênio (DBO), temperatura da água, nitrogênio total, fósforo total, turbidez e resíduo total. Todos estes parâmetros devem estar de acordo com o estabelecido pela Resolução CONAMA 357/2005 (BRASIL, 2005) que dispõe a respeito da classificação dos corpos de água no país, estabelece as condições e padrões de lançamento de efluentes. Para a lagoa da ETA considera- se a classificação como Classe II.

A extração de areia é uma atividade econômica promovida para a construção civil em todas as unidades da federação, sendo as formas de extração realizadas por desmonte hidráulico (em cavas próximas a área de várzea) e por extração de cava submersa (extração em leitos de rios) (BRASIL, 2013 apud SILVA, 2016).

A extração mineral é responsável pela degradação do meio físico, causando a supressão de vegetação, o desaparecimento da fauna local, a esterilização do terreno pela contaminação superficial e subterrânea com óleos e graxas, além do assoreamento e rebaixamento do leito do rio (GARDNER, 2001 apud SILVA, 2016).

As antigas cavas de areia localizadas na UNIVAP, apresentaram-se com níveis de erosão e assoreamento altos nas lagoas que foram objeto de extração durante anos, utilizando-se do método de cava submersa que consiste na extração por meio de dragas instaladas no barco e equipada com uma bomba centrífuga. Existem tubos acoplados a essas bombas servindo como condutores e transportadores da polpa retirada até o pátio, onde fica o dique que receberá o material com excesso de umidade. Essa área foi adquirida pela instituição no ano de 2003, que se tornou responsável pelo passivo ambiental deixado, sendo realizado pela mesma o plano de recuperação ambiental para as áreas antigamente extrativas, todas estão em processo de recuperação, estando algumas em estágios mais avançados e outras mais lentas, sendo em especial apresentada neste trabalho a lagoa da ETA apresentando-se recuperada e monitorada (CÔMITE DE BACIAS HIDROGRÁFICAS DO RIO PARAÍBA DO SUL, 2009).

Para se recuperar uma área antigamente ocupada por atividade de mineração é impossível que se volte ao estado original da superfície explorada, o que pode ser feito é encontrar maneiras de uso produtivo para essas áreas. Recuperar uma área exige 
técnicas de manejo que tornem o solo produtivo ou sustentável que estejam em um equilíbrio físico, químico e biológico com a vizinhança (SANCHEZ, 2008).

Neste sentido, o presente trabalho tem por objetivo avaliar a qualidade da água de uma lagoa de mineração que provê o abastecimento de água do Campus Urbanova da Universidade do Vale do Paraíba (UNIVAP), segundo parâmetros estabelecidos pelo IQA (BRASIL,2005).

\section{MATERIAIS E MÉTODOS}

\subsection{Caracterização do ambiente de estudo}

Localizada nos limites do campus Urbanova da Univap a lagoa de mineração em estudo encontra-se em um local com declividade pouco acentuada, na área de várzea do Rio Paraíba do Sul, sendo margeada por este na sua porção sudoeste (Figura 1). Seu solo possui característica arenosa, sendo mais propicia a infiltração de água pelos espaçamentos contidos entre os grãos.

Figura 1 - Localização da lagoa a ser estudada.

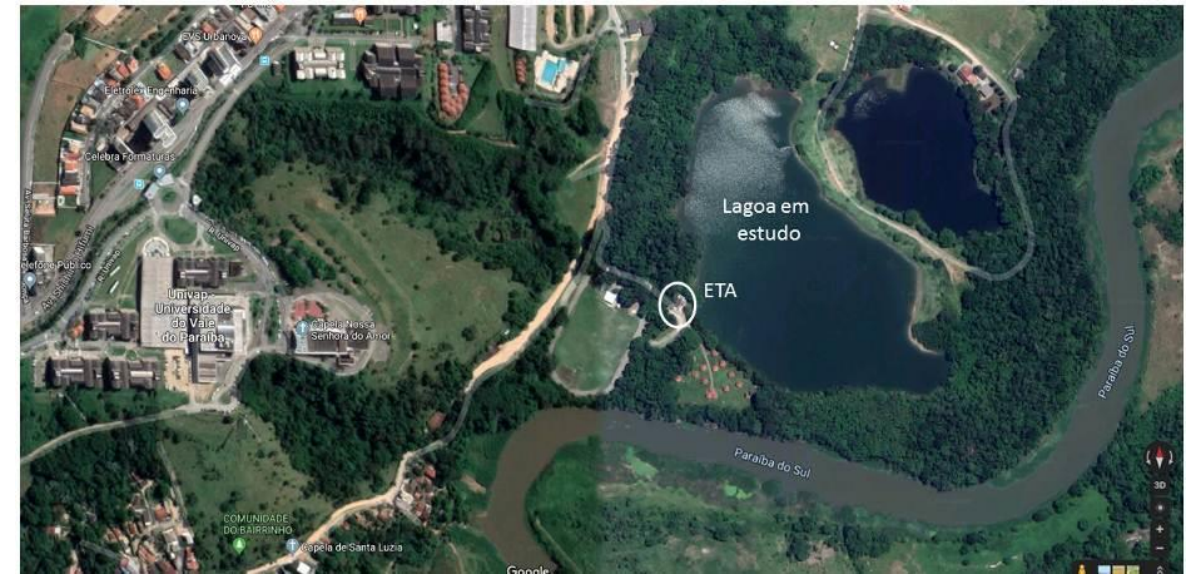

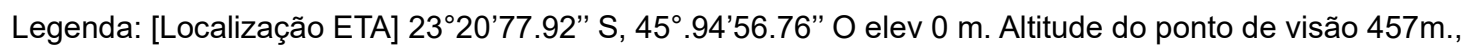
20 ago. 2018

Fonte: GOOGLE EARTH, 2018a.

Em São José dos Campos, a classificação climática de Köppen e Geiger é clima úmido em todas as estações, com verão quente ( $\mathrm{Cfa}$ ) sendo a temperatura média $19.4^{\circ} \mathrm{C}$ e a pluviosidade média anual $1269 \mathrm{~mm}$ (CLIMATE-DATA.ORG, 2018).

\subsection{Coleta de água}

Foram realizadas coletas (setembro de 2018) de água no ponto amostral sob coordenadas geográficas latitude $-23^{\circ} .25^{\prime} .85^{\prime \prime} \mathrm{S}$ e longitude $-45^{\circ} .94^{\prime} .65^{\prime \prime} \mathrm{O}$, com profundidade total de $8,5 \mathrm{~m}$ dos quais $2,5 \mathrm{~m}$ caracterizaram a zona eufótica (presença de luz) e 6,0 m caracterizando a zona afótica (ausência de luz). A figura 2 apresenta a vista geral do ponto de coleta, as quais foram realizadas no período da manhã de cada 
dia de coleta, em triplicata, considerando superfície e meio.

Figura 2 - Ponto de coleta.

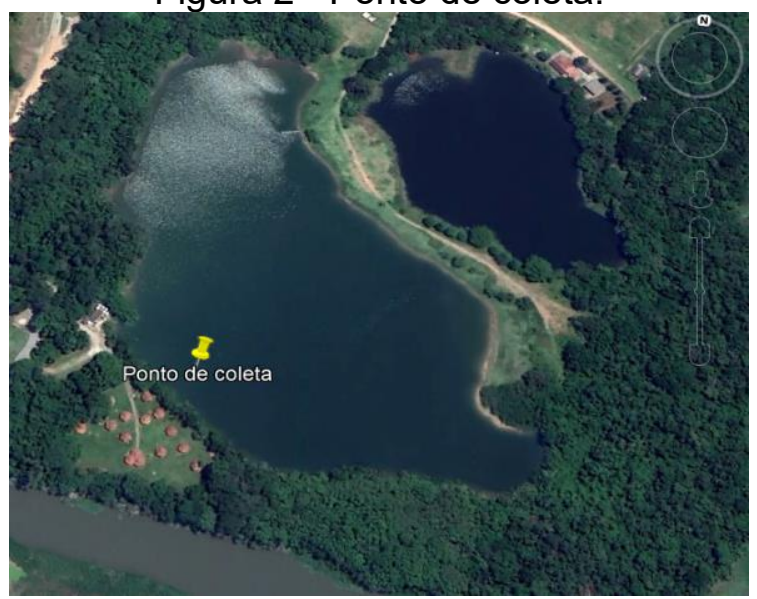

Legenda: [Ponto de coleta ETA] 2312'31.11"S, 4556'46.44"O elev 0m. Altitude do ponto de visão 515 m., 20 ago. 2018.

Fonte: GOOGLE EARTH, 2018b.

Para a realização das coletas foram utilizados: bote, remo, colete salva-vidas, garrafa de Van dorn, disco de secchi, garrafas de plástico de $500 \mathrm{~mL}$ e frasco de vidro esmerilhado de $300 \mathrm{Ml}$ (figura 3).

Figura 3 - Materiais utilizados durante a coleta: A) Bote e Garrafa de Van Dorn B) Frasco Esmerilhado de $300 \mathrm{ml}$, Garrafa de Plástico $500 \mathrm{ml}$ e remo C) Disco de Secchi

D) Lagoa ETA (UNIVAP) e E) Colete salva-vidas.

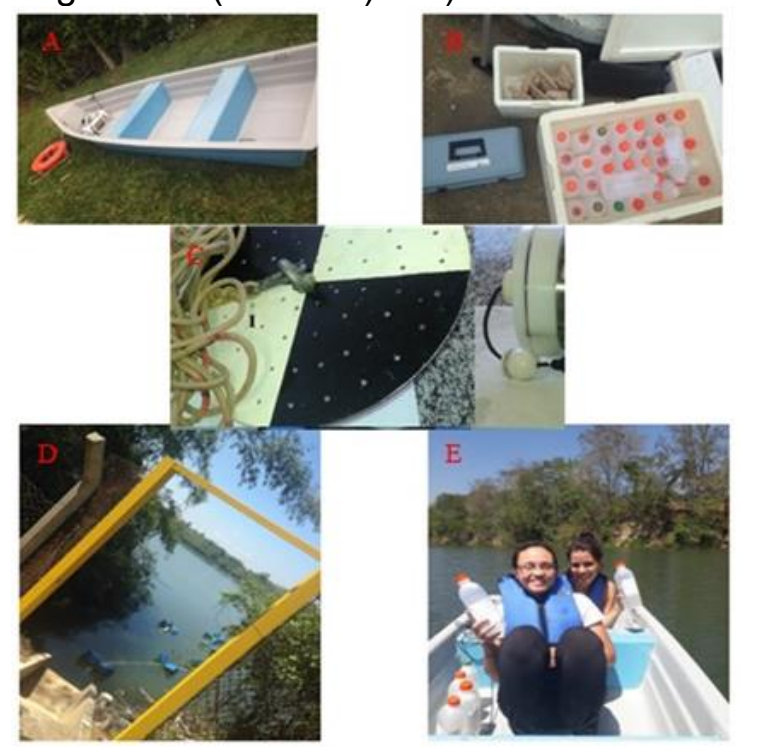

Fonte: Os autores.

Após a coleta, os frascos com as amostras de água foram mantidos em uma caixa de isopor com gelo, a fim de preservar as características químicas das amostras coletadas. Em campo, foram avaliados $\mathrm{pH}, \mathrm{OD}$ e temperatura utilizando o aparelho Multiparâmetro pIONneer 65, seguindo orientações da Cetesb (SÃO PAULO, 2011). Ao final da coleta, todo material foi transportado para o laboratório de ciências ambientais (IP\&D/Univap) para realização das análises laboratoriais. 


\subsection{Parâmetros analisados}

Desconsiderando-se os parâmetros avaliados em campo (oxigênio dissolvido, $\mathrm{pH}$ e temperatura da água), os demais parâmetros que constituem o IQA tais como: coliformes termotolerantes, demanda bioquímica de oxigênio (DBO), nitrogênio total, fósforo total, turbidez e resíduo totais, foram realizados segundo Standard Methods for the Examination of Water and Wastewater (STANDARD METHODS FOR THE EXAMINATION OF WATER AND WASTEWATER, 2012).

\section{RESULTADOS E DISCUSSÃO}

A quantidade de oxigênio dissolvido na água para uma qualidade boa é igual a 5 $\mathrm{mg} / \mathrm{l}$, abaixo desse valor é considerado prejudicial à saúde dos microrganismos que necessitam de oxigênio para sobreviver, já acima, não se tem problema. Porém, de acordo com o volume de chuva e velocidade do vento, ocorre à dispersão ou acumulo de oxigênio na água, sendo essa quantidade presente, aumentada ou diminuída, dependendo de cada situação a qual se encontra no dia da coleta. Segundo a resolução CONAMA 357/05, a quantidade de oxigênio mínima permitida é de $5 \mathrm{mg} / \mathrm{l}$ (BRASIL, 2005). Os resultados obtidos para oxigênio dissolvido são apresentados conforme gráfico 1.

Gráfico 1 - Valores médios para superfície e meio de OD.

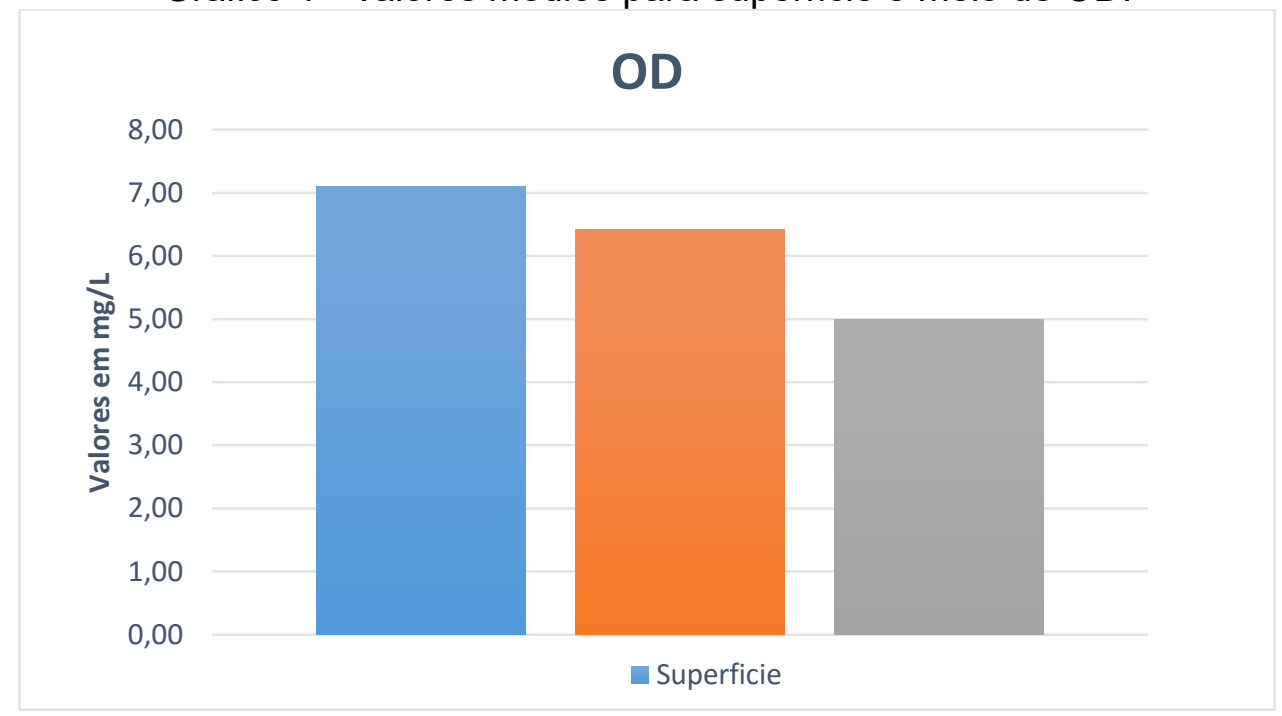

Fonte: Os autores.

Assim, foi possível verificar que os valores de OD se encontram acima do estipulado, o que indica maior quantidade de nutrientes, mas não é considerado prejudicial, podendo aquela região ter um nível de competição menor, maior presença de luz e menos matéria orgânica na água de acordo com um volume de chuva maior e uma velocidade do vento também maior, sendo esses responsáveis pela dispersão e diluição mais rápida da matéria orgânica. 
$\mathrm{O}$ pH chamado de potencial hidrogeniônico é a capacidade que um ácido tem de liberar íons $\mathrm{H}^{+}$na água. Para a saúde humana considera-se que o $\mathrm{pH}$ da água deve estar em meio alcalino, uma vez que na geração de energia consome elétrons, o que acarreta a produção de prótons $\mathrm{H}^{+}$e para equilibrar essa quantidade ácida se deve ter uma quantidade básica no organismo. Por esse motivo, segundo a resolução CONAMA 357/05 que estipula valores teóricos permitidos em rios, em relação aos rios classe 2, a faixa de $\mathrm{pH}$ deve ser em torno de 6 a 9 (BRASIL, 2005). O gráfico 2 apresenta os resultados de $\mathrm{pH}$ avaliado para o sistema de estudo.

Gráfico 2 - Valores médios para superfície e meio de $\mathrm{pH}$.

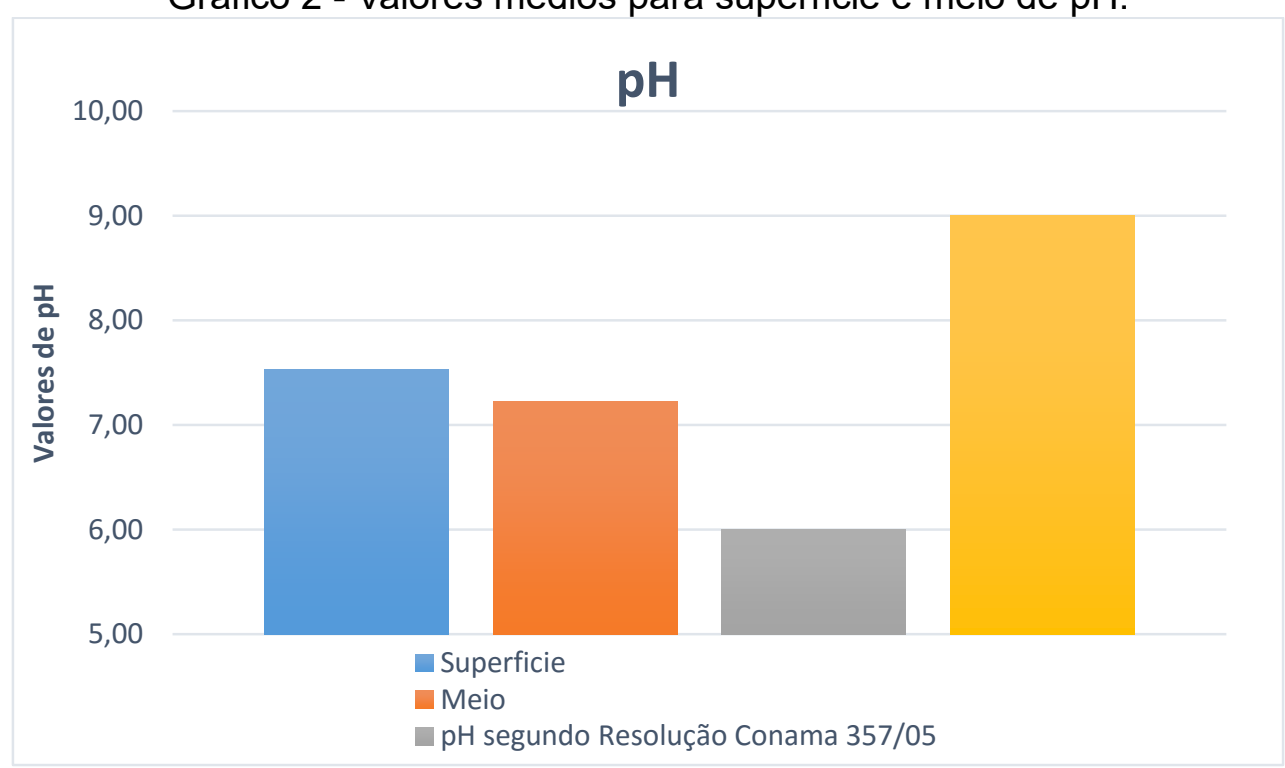

Fonte: Os autores.

Segundo a resolução CONAMA águas potáveis, ou seja, de classe 1 e 2, devem estar na faixa de pH entre 6 e 9 , sendo possível notar que os pontos coletados estão de acordo com a faixa estipulada pela legislação vigente. Esse índice nos mostra apenas que o pH da água está ácido ou básico e dependendo da espécie aquática que vive na região ela pode ser sensível a faixas de $\mathrm{pH}$, o que pode prejudicar sua sobrevivência.

A DBO é representada pela quantidade de oxigênio consumida na degradação da matéria orgânica na água. Segundo a resolução CONAMA 357/2005, a quantidade máxima de DBO permitida na água é de $5 \mathrm{mg} / \mathrm{L}$ (BRASIL, 2005). Os valores obtidos para DBO se apresentam conforme gráfico 3. 
Gráfico 3 - Valores médios para superfície e meio de DBO.

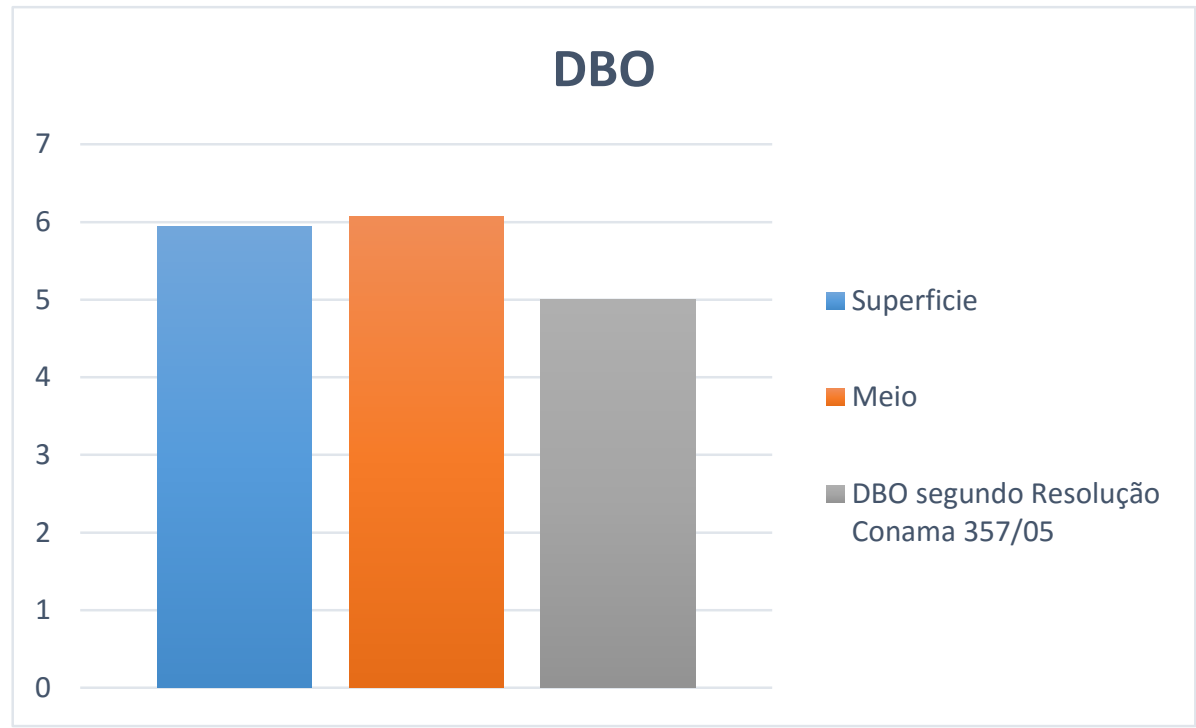

Fonte: Os autores.

A DBO é representada pela quantidade de oxigênio consumida na degradação da matéria orgânica na água. Como é possível notar, os pontos de superfície e meio se apresentam em quantidade acima do estipulado pela resolução CONAMA 357/2005, o que pode indicar quantidade de matéria orgânica superior na água (BRASIL, 2005).

Von Sperling (2005) afirma que a temperatura é a medição da intensidade de calor e, no sistema aquático, a temperatura da água está muito relacionada com a capacidade de sobrevivência dos seres vivos. A variação de temperatura faz parte do regime climático normal, e corpos de água naturais apresentam variações sazonais e diurnas, bem como estratificação. Os valores para a temperatura da água se apresentam conforme o gráfico 4.

Gráfico 4 - Valores médios para superfície e meio de Temperatura.

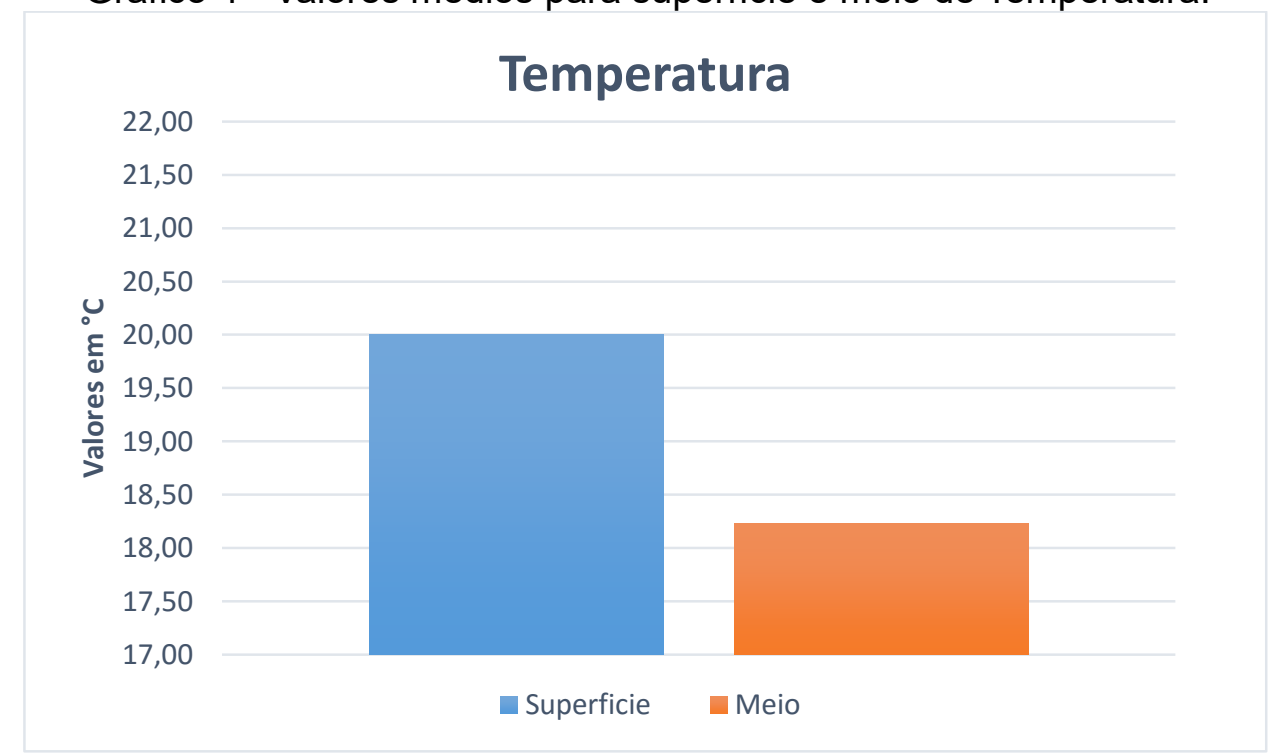

Fonte: Os autores. 
Como pode ser observada no gráfico, a temperatura permanece na faixa de $17,5 / 21^{\circ} \mathrm{C}$, o que indica uma boa temperatura, visto que o clima na região se apresenta com temperaturas na faixa dos $19 / 30^{\circ} \mathrm{C}$, sendo assim os organismos presentes no ambiente, especificamente peixes no local estudado, são adaptados às temperaturas encontradas.

O nitrogênio amoniacal é considerado um dos elementos para a indicação de poluição de um rio, após a decomposição aeróbia do nitrogênio amoniacal ele é transformado primeiramente em nitrito e depois em nitrato. A presença elevada de nitrogênio com nitrito e nitrato na água indica que a poluição aconteceu há certo período (ZOPPAS; BERNARDES; MENEGUZZI, 2018). Segundo a resolução CONAMA 357/05, a quantidade máxima de nitrogênio amoniacal depende da faixa de $\mathrm{pH}$, assim temos: $3,7 \mathrm{mg} / \mathrm{L} \mathrm{N}$, para $\mathrm{pH} \leq 7,5 ; 2,0 \mathrm{mg} / \mathrm{L} \mathrm{N}$, para $7,5<\mathrm{pH} \leq 8,0 ; 1,0 \mathrm{mg} / \mathrm{L} \mathrm{N}$, para $8,0<\mathrm{pH} \leq$ 8,$5 ; 0,5 \mathrm{mg} / \mathrm{L} \mathrm{N}$, para $\mathrm{pH}>8,5$ (BRASIL, 2005). Os valores para nitrogênio total se apresentam conforme o gráfico 5 .

Gráfico 5 - Valores médios para superfície e meio de Nitrogênio.

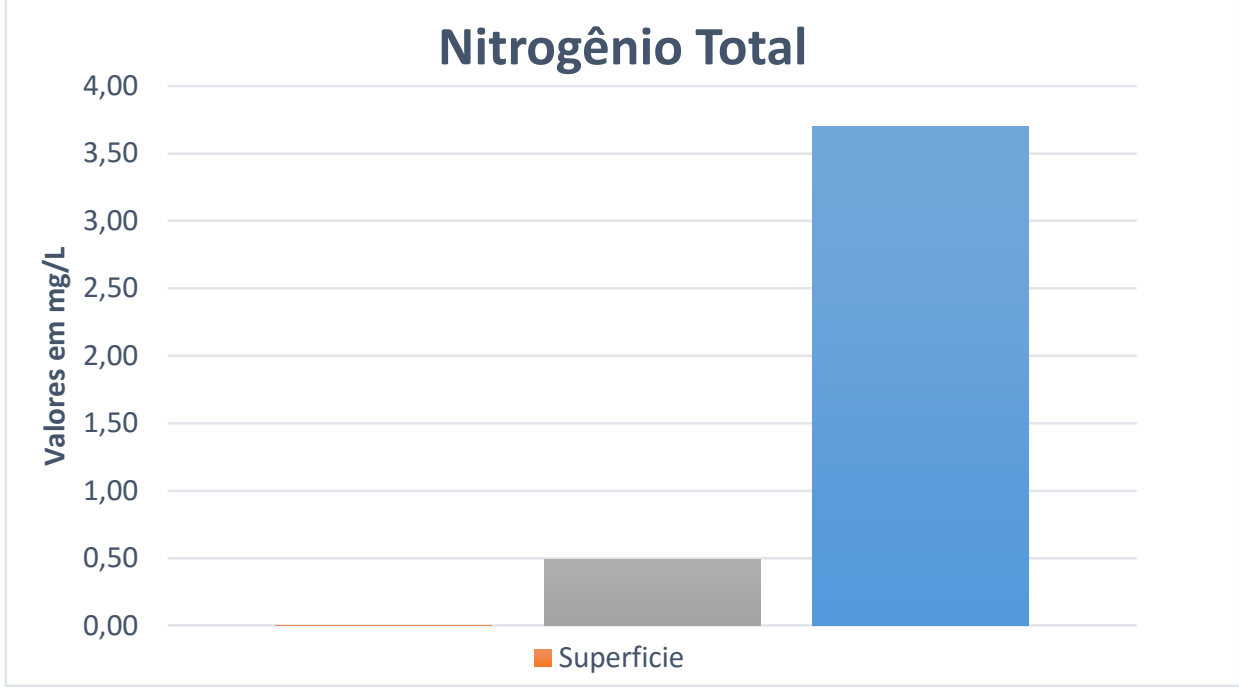

Fonte: Os autores.

Assim, é possível notar que os valores de nitrogênio estão bem abaixo do estipulado, sendo um indicativo de que a região não apresenta sinais de poluição por conta da decomposição do nitrogênio, mostrando que a água está em condições de consumo desde que haja devido tratamento.

O fósforo em contato com a água se torna um fator de risco quando se fala em processos de eutrofização. É essencial nos processos de metabolismo dos organismos, porém em excesso potencializa os efeitos eutrofizantes nos corpos d'água (DELLAGIUSTÍNA, 2000). Segundo a resolução CONAMA 357/05, o nível tolerável de fósforo total presente na água é de $0,1 \mathrm{mg} / \mathrm{l}$ (isso para ambientes lóticos) (BRASIL, 2005). O gráfico 6 apresenta os resultados de Fósforo Total. 
Gráfico 6 - Valores médios para superfície e meio de Fósforo Total.

\section{Fósforo Total}

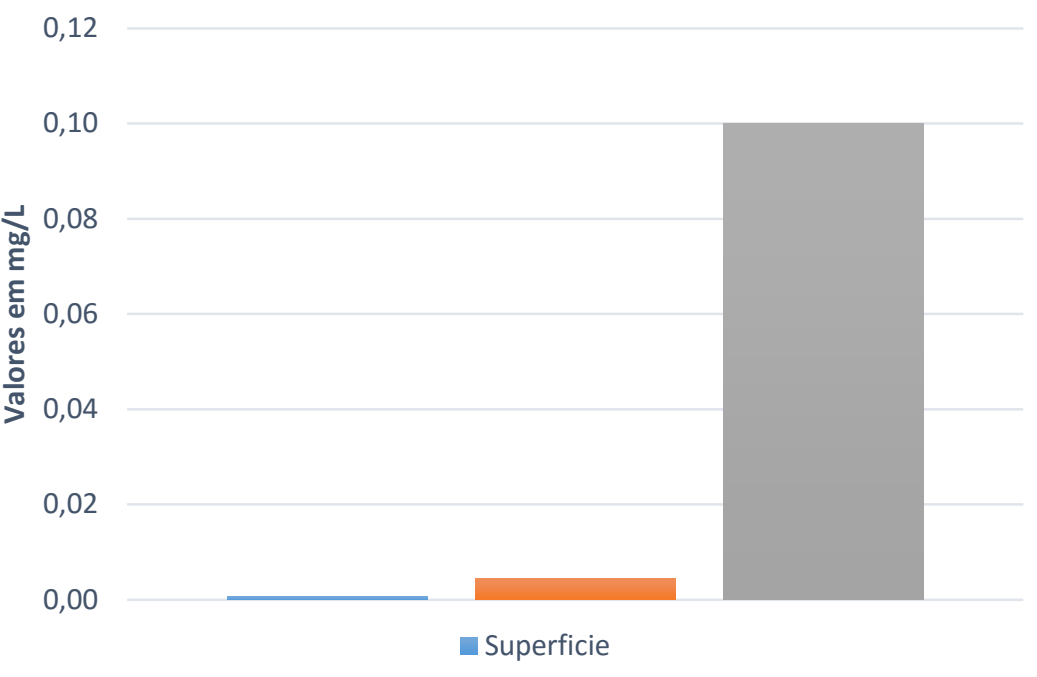

Fonte: Os autores.

Sabe-se que o fósforo é um elemento essencial para a sobrevivência das espécies em geral, pois ele auxilia no processo de metabolismo. Mas, em excesso, ele é prejudicial por conta de avançar o processo de eutrofização dos rios. No gráfico, é possível ver que em todos os pontos coletados está presente uma quantidade abaixo da permitida pela legislação, sendo quase ausente o que indica que a lagoa não sofre risco de avanço do processo de eutrofização.

Turbidez é determinada pela ausência da passagem de luz na água, o que implica uma série de fatores, como a presença de oxigênio por meio da fotossíntese, a presença de compostos contaminantes ou tóxicos, quando mais na parte escura a presença de luz não é tão predominante. Segundo a resolução CONAMA 357/2005 a quantidade máxima de turbidez permitida na água é de 100 UNT (BRASIL, 2005). O gráfico 7 apresenta os resultados de Turbidez. 
Gráfico 7 - Valores médios para superfície e meio de Turbidez.

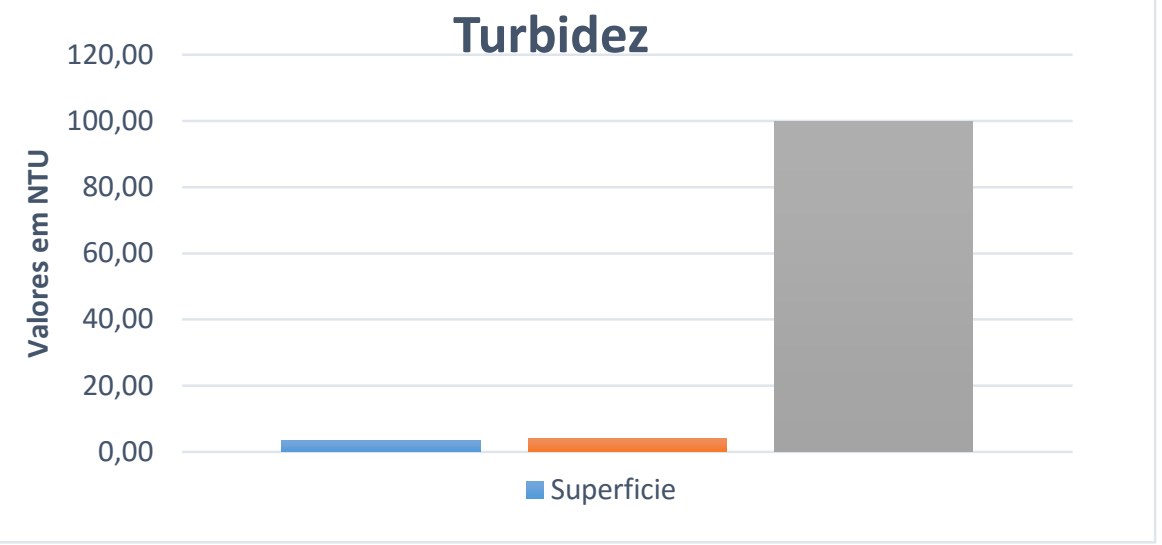

Fonte: Os autores.

Como é possível ver no gráfico, todos os pontos apresentam valores abaixo do valor recomendado pela resolução CONAMA 357/2005, o que não implica uma presença de água turva na área, não prejudicando a vida dos peixes que habitam naquele local. Em certas regiões, a presença de turbidez é maior, o que pode ser prejudicial a vida aquática naquele local.

Sólidos Totais é a quantidade de substâncias orgânicas e inorgânicas na água, o que pode ser prejudicial, pois envolve carbonatos, bicarbonatos, cloretos, sulfatos e assim por diante. Pode indicar que uma água está com processor de dureza, uma vez que envolve a quantidade de íons cálcio e magnésio na água. Segundo a Resolução CONAMA 430/11, o valor máximo para sólidos na água é de 500 mg/L (BRASIL, 2011). O gráfico 8 apresenta os resultados de Sólidos Totais.

Gráfico 8 - Valores médios para superfície e meio de Sólidos Totais*.

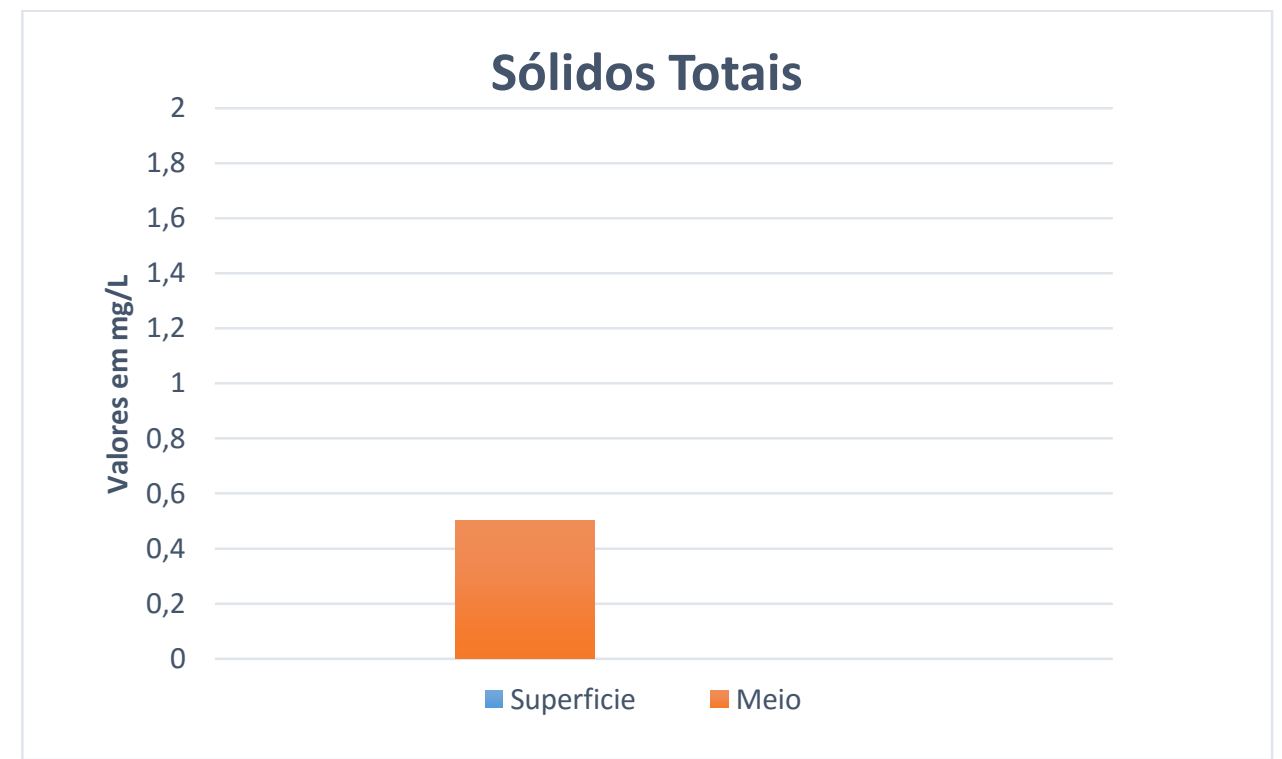

*O valor máximo permitido pela Resolução Conama 430/11 é de 500 mg/L, porém no gráfico esse valor extrapola pelo fato da quantidade de sólidos na água ser pequena.

Fonte: Os autores. 
Como é possível notar no gráfico, a quantidade de sólidos na água é abaixo do estipulado pela legislação Conama 430/2011, que indica um valor permitido de $500 \mathrm{mg} / \mathrm{L}$ e basicamente inexistente, apresentando uma água sem a presença de substâncias orgânicas e inorgânicas, não sendo uma água dura (BRASIL, 2011).

Coliformes fecais são indicadores de contaminação fecal na água, a mais utilizada é a E.Coli indicando a presença de organismos patogênicos na água, vírus ou organismos que apresentem poder de contaminação. A presença de coliformes é danosa à saúde humana, mostrando que a água contaminada não pode ser consumida (PORTAL SÃOFRANCISCO, 2017). A presença de coliformes fecais se dá pela presença de esgoto na água ou dejetos liberados de forma inapropriada. Segundo a resolução CONAMA 274/00 para uma água considerada própria e satisfatória se tem um máximo de 1000 coliformes fecais permitidos (BRASIL, 2000). No processo de análise de água não se encontrou presença de Coliformes Totais.

Todos os resultados encontrados referentes aos parâmetros para o cálculo do IQA, bem como o seu valor podem ser observados a seguir.

No momento das coletas realizadas os parâmetros de temperatura, $\mathrm{pH}$ e OD foram medidos, sendo as médias de cada um desses apresentada de acordo com a Tabela 1.

Tabela 1 - Valores médios para pH, OD e Temperatura.

\begin{tabular}{ccccc}
\hline Amostras & $\begin{array}{c}\text { Temperatura } \\
{ }^{\circ} \mathrm{C}\end{array}$ & $\mathrm{pH}$ & $\mathrm{OD}(\mathrm{mg} / \mathrm{L})$ & $\begin{array}{l}\text { Temperatura após } \\
\text { análise de OD }{ }^{\circ} \mathrm{C}\end{array}$ \\
\hline Superfície & 26 & 8,1 & 9,0 & 22,9 \\
Meio & 25,5 & 7,9 & 10,4 & 21,9 \\
\hline
\end{tabular}

Fonte: Os autores.

Para o cálculo do IQA foi utilizado o software Qualigraf, sendo os valores médios apresentados conforme Tabela 2.

Tabela 2 - Valores médios de IQA para a superfície e meio.

\begin{tabular}{ccc}
\hline Amostras & $\begin{array}{c}\text { Valores Segundo } \\
\text { Tabela IQA }\end{array}$ & Qualidade* $^{*}$ \\
\hline Sup. 22-09 & 92 & Ótima \\
Meio 22-09 & 93 & Ótima \\
Sup. 29-09 & 92 & Ótima \\
Meio. 29-09 & 86 & Ótima \\
\hline
\end{tabular}

Fonte: Os autores. 


\section{CONCLUSÃO}

As avaliações aqui realizadas refletem que a lagoa de mineração em estudo atende aos requisitos legais estabelecidos pelo Conselho Nacional do Meio Ambiente, no que se refere as suas resoluções CONAMA n³57/05 (BRASIL, 2005) e CONAMA $n^{\circ} 430 / 11$ (BRASIL, 2011), sendo segundo estas, classificada como Classe II podendo atender a população como manancial de abastecimento público. Adicionalmente, os resultados aqui obtidos indicam, segundo Índice de Qualidade da Água, que o ambiente de estudo está classificado com qualidade ótima, ou seja, IQA = 90 (SÃO PAULO, 2008)

No que se refere ao uso, como a prática de mergulho, a natação, esqui aquático, há necessidade de avaliar outros parâmetros estabelecidos pela Resolução CONAMA Nº 274 de 2000 (BRASIL, 2000). Vale ressaltar que análises devem ser feitas em relação ao solo depositado no fundo da Lagoa, uma vez que esses sedimentos são provenientes da atividade antigamente mineraria exercida na área em questão.

\section{REFERÊNCIAS}

BRASIL. CONAMA. Resolução nํㅜ 357, de 18 de março de 2005. Diário Oficial da União, Brasília, 2005. Disponível em:

http://www2.mma.gov.br/port/conama/res/res05/res35705.pdf. Acesso em: 21 ago. 2018.

BRASIL. CONAMA. Resolução no 430, de 16 de maio de 2011. Diário Oficial da União, Brasília, 2011. Disponível em:

http://www2.mma.gov.br/port/conama/res/res11/res43011.pdf. Acesso em: 21 ago. 2018.

BRASIL. CONAMA. Resolução n²74, de 29 de novembro de 2000. Diário Oficial da União, Brasília, 2000. Disponível em:

http://www2.mma.gov.br/port/conama/res/res00/res27400.html. Acesso em: 21 ago. 2018.

BRASIL. Agência Nacional de Águas. Indicadores de qualidade: índice de qualidade das águas (IQA). 2018. Disponível em: http://pnqa.ana.gov.br/indicadores-indiceaguas.aspx. Acesso em: 20 ago. 2018.

CLIMATE-DATA.ORG. Clima São José dos Campos. 2018. Disponível em: https://pt.climate-data.org/location/6151/. Acesso em: 20 ago. 2018.

COMITÊ DAS BACIAS HIDROGRÁFICAS DO RIO PARAÍBA DO SUL. Exploração de areia no Vale do Paraíba: problemas e soluções. São Paulo: CBH-PS - Comitê das Bacias Hidrográficas do Rio Paraiba do Sul, 2009.

DELLAGIUSTÍNA, A. Determinação das concentrações de nitrogênio e fósforo dissolvidos em diferentes locais do Rio Itajaí-açu. 2000. 92 f. Dissertação (Mestrado em Química Analítica) - Universidade Federal de Santa Catarina, Florianópolis, 2000. 
GOOGLE EARTH. [Localização ETA]: 23ำ2'77'.92"S 459'ㄷ⒍76"O elev 0 m. Atitude do ponto de visão 457m., 20 ago. 2018.

GOOGLE EARTH. [Ponto de coleta ETA]: 231''1'.11"S 455'ㄴ'46.44" O elev 0 m. Atitude do ponto de visão 515m., 20 ago. 2018b.

2011.PORTAL SÃO FRANCISCO. Coliformes. São Francisco. São Paulo, p. 1-10. maio 2017. Disponível em: http://www.portalsaofrancisco.com.br/biologia/coliformes. Acesso em: 21 ago. 2018.

RICHTER, C. A. Água: Métodos e Tecnologia de Tratamento. São Paulo: Edgard Blucher Ltda, 2009.

SÁNCHEZ, Luiz enrique. Avaliação de impacto ambiental: conceitos e métodos. Oficina de textos, 2008.

SÃO PAULO. CETESB. Qualidade das Águas Interiores do Estado de São Paulo. São Paulo: Cetesb, 2008.

SÃO PAULO. CETESB. Guia Nacional De coleta e Preservação De amostras: Água, Sedimento, Comunidades aquáticas e efluentes líquidos. São Paulo: Cedoc, 2011.

SILVA, A. A.M. Avaliação da Qualidade Ambiental de Áreas Degradadas em Recuperação: Fazenda do Poço (Jacareí/SP) - Um Estudo de Caso. 2016.

Dissertação (Mestrado em Engenharia Biomédica) - Universidade do Vale do Paraíba, São José dos Campos, 2016.

STANDARD METHODS FOR THE EXAMINATION OF WATER AND WASTEWATER, 22nd. ed. 2012. Disponível em: http://www.sciepub.com/reference/226577. Acesso em: 20 ago. 2018.

VON SPERLING, M. Introdução à qualidade das águas e ao tratamento de esgotos. 3 ed. Belo Horizonte: Editora da Universidade Federal de Minas Gerais UFMG -, 2005.

ZOPPAS, F. M.; BERNARDES, A. M.; MENEGUZZI, A. Parâmetros operacionais na remoção biológica de nitrogênio de águas por nitrificação e desnitrificação simultânea. Revista Eng Sanit Ambient., v. 21, n. 1, p. 29-42, 2016. Disponível em: http://www.scielo.br/pdf/esa/v21n1/1413-4152-esa-21-01-00029.pdf. Acesso em: 29 maio 2018. 